\title{
Effect of Evernic Acid on Structure of Spinach Chloroplasts
}

\author{
S. RAPSCH and C. ASCASO \\ Instituto de Edafologia y Biologia Vegetal, Serrano 115 bis, Madrid 28006, Spain
}

Accepted: 9 May 1985

\begin{abstract}
Detached leaves of Spinacia oleracea were incubated with evernic acid, the main phenolic substance present in Evernia prunastri thalli. This lichen substance produced a decrease in the amount of total chlorophyll and chlorophyll a in treated spinach leaves. Chloroplast structure suffered a decrease in several parameters, i.e. chloroplast area, number of grana, granal width, number of thylakoids per granum and starch content. The submicroscopic structure of the chloroplast membranes revealed smaller particle diameters in several of the fracture faces in the evernic acid treated samples and even a decrease in the density of particles in the $\mathrm{EF}_{\mathrm{s}}$ fracture face. The alterations observed may be related to changes in photosynthetic activity, probably by modification of both photosystem I and photosystem II activities.
\end{abstract}

Key words: Evernic acid, chloroplast structure, TEM, thylakoidal membrane, freeze-etching, chlorophyll content.

\section{INTRODUCTION}

Lichens as epiphytic autotrophs can have harmful effects on trees (Richardson, 1974). The destruction of corticolous lichens growing on fruit trees is a common practice in several parts of the world, in the belief that lichen-free trees are more robust (Hale, 1983). Epiphytic communities of lichens seem to produce an inhibition of tea shoot development (Asahina and Kurokawa, 1952) as well as a partial or complete defoliation of phorophyte in the wild holm-oak woods of Central Spain (Estevez et al., 1982; Ascaso et al., 1983).

Epiphytic lichens may penetrate the phorophyte tissues, reaching as far as the xylem (Ascaco et al., 1980; Orus and Ascaso, 1982). Under natural conditions, the phenolic substances produced by lichens can potentially reach conducting tissues of the tree. The toxicity of such lichen phenolic substances has been demonstrated under laboratory conditions (Ramaut and Thonar, 1972 $a, b$; Dauriac and Rondon, 1976). Moreover, phenolic substances isolated from the Evernia prunastri thallus and added to the incubation medium of detached leaves of Quercus rotundifolia inhibited photosystem II electron flow (Orus et al., 1981) and affected the ultrastructure of the chloroplasts (Ascaso et al., 1983).

Several authors have employed ultrathin sections and freeze-fracturing electron microscopy (Goodenough and Staehelin, 1971; Miller and Cushman, 1979; Miller, 1980; Popov et al., 1981) to examine the supramolecular organization of the thylakoid membranes. Considering that chloroplast structure and function are intimately connected, our study concentrated on ultrastructural chloroplast changes in spinach leaves produced by evernic acid, which is the most abundant phenolic substance found in the $E$. prunastri thallus.

\section{MATERIAL AND METHODS}

Detached spinach leaves (obtained commercially) were incubated for one week with evernic acid (Sigma, 35.5 $\mu \mathrm{M}$ ) in $1 \mathrm{~mm} \mathrm{NaHCO}_{3} \mathrm{pH}$ 6.5. Samples incubated in the 
bicarbonate solution without evernic acid were used as controls. In both cases detached leaves take up the solution through the petioles in the transpiration stream.

\section{Chlorophyll determinations}

Chloroplasts were isolated according to the method of Whatley and Arnon (1963). Chlorophyll determinations were made from 80 per cent acetone extracts of the material using Arnon's (1949) equations to calculate chlorophyll $a, b$ and total chlorophyll concentration.

\section{Electron microscopy}

After treatment, leaf pieces of about $1 \mathrm{~mm}^{2}$ were fixed in 3.25 per cent glutaraldehyde

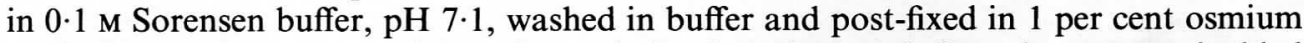
tetroxide. Dehydration was done in graded series of ethanol. Samples were embedded in Spurr's medium (Spurr, 1969) and polymerized at $70^{\circ} \mathrm{C}$ for $24 \mathrm{~h}$. Sectioning was carried out with an Ultracut-E Reichert Ultratome. The sections were stained with lead citrate according to Reynolds (1963) for $6 \mathrm{~min}$ at $20^{\circ} \mathrm{C}$.

\section{Freeze-etching}

The submicroscopic structure of the chloroplast membranes was studied as described by Moor and Mühlethaler (1963). The chloroplasts were isolated from the spinach leaves after treatment. The chloroplast membranes were infiltrated with glycerol as a cryoprotectant, final concentration of $25-30$ per cent for $1 \mathrm{~h}$ at $4{ }^{\circ} \mathrm{C}$. Droplets of chloroplast membranes were frozen for $10 \mathrm{~s}$ with Freon 22, and stored in liquid nitrogen. The freeze-fracture was carried out at $-110^{\circ} \mathrm{C}$ and after the temperature reached $-100^{\circ} \mathrm{C}$, samples were etched for $3 \mathrm{~s}$. The replicas were cleaned in 50 per cent nitric acid plus potassium bichromate for $2 \mathrm{~d}$ and then in distilled water.

Ultrathin sections and freeze-etched replicas were examined with a Philips EM 300 electron microscope. Image analysis was carried out with a Mop-Videoplan (Kontron) semiautomatic image analyser.

\section{RESULTS}

Visual inspection showed that incubation with evernic acid induced the symptoms of chlorosis and desiccation in spinach leaves.

The total chlorophyll and chlorophyll $a$ content as well as the ratio chlorophyll $a$ /chlorophyll $b$ decreased in the evernic acid treated samples (Table 1), whilst chlorophyll $b$ content increased slightly.

The leaves of $S$. oleracea by TEM showed the typical arrangement of the cells of leaf

TABLE 1. Photosynthetic characteristics of chloroplasts from control and evernic acid-treated spinach leaves

\begin{tabular}{lcccc}
\hline & $\begin{array}{c}\text { Total chlorophyll } \\
\left(\mu \mathrm{g} \mathrm{g}^{-1} \text { f.wt) }\right.\end{array}$ & $\begin{array}{c}\text { Chlorophyll } a \\
\left(\mu \mathrm{g} \mathrm{g}^{-1} \text { f.wt }\right)\end{array}$ & $\begin{array}{c}\text { Chlorophyll } b \\
\left(\mu \mathrm{g} \mathrm{g}^{-1} \text { f.wt }\right)\end{array}$ & Chl $a /$ Chl $b$ \\
\hline Control & $1032 \cdot 2 \pm 47 \cdot 0$ & $614 \cdot 3 \pm 25 \cdot 0$ & $417 \cdot 8 \pm 22 \cdot 0$ & $1 \cdot 47$ \\
Evernic acid & $900 \cdot 1 \pm 47 \cdot 2$ & $431 \cdot 2 \pm 24 \cdot 4$ & $468 \cdot 8 \pm 25 \cdot 0$ & 0.92 \\
\hline
\end{tabular}

Means \pm s.d. 
TABLE 2. Differences in the ultrastructure of chloroplasts from spinach leaves incubated in bicarbonate solution (control) and in evernic acid in bicarbonate solution (evernic acid)

\begin{tabular}{|c|c|c|}
\hline Parameter & Control & Evernic acid \\
\hline Area of chloroplasts $\left(\mu \mathrm{m}^{2}\right)$ & $6 \cdot 58 \pm 1 \cdot 50^{*}$ & $3 \cdot 71 \pm 1 \cdot 61^{*}$ \\
\hline $\begin{array}{l}\text { Average number of grana } \\
\text { per chloroplast }\end{array}$ & $23 \cdot 67 \pm 6 \cdot 30^{*}$ & $18 \cdot 14 \pm 3 \cdot 84^{*}$ \\
\hline Average granal width $(\mathrm{nm}) \dagger$ & $117 \cdot 50 \pm 53 \cdot 4^{*}$ & $100 \cdot 90 \pm 51 \cdot 6^{*}$ \\
\hline $\begin{array}{l}\text { Average number of thylakoids } \\
\text { per granum } \dagger\end{array}$ & $5 \cdot 96 \pm 2 \cdot 96^{* *}$ & $5 \cdot 30 \pm 2 \cdot 87^{* *}$ \\
\hline $\begin{array}{l}\text { Percent starch content per } \\
\text { chloroplast section (starch } \\
\text { area as } \% \text { of chloroplast area) }\end{array}$ & 1.94 & $0 \cdot 81$ \\
\hline
\end{tabular}

Means \pm s.d., based on 100 median chloroplast sections.

Values of a specific feature are statistically different $(t$-test) at $* P<0.01 ; * * P<0.05$.

$\dagger$ Based on 165 grana stacks.

tissue: uper epidermis, palisade and spongy parenchyma and lower epidermis. Since the cells of the spongy parenchyma are very near the vascular bundle, the present study focuses on the chloroplasts of these cells. The evernic acid-treated chloroplasts had a lower starch content, were smaller in area, contained fewer grana per chloroplast section and the grana stacks were narrower and contained fewer thylakoids (Table 2).

Freeze-fracturing splits membranes along their hydrophobic interior. The two complementary fracture faces are named according to the terminology of Branton et al. (1975), $\mathrm{PF}$ for the protoplasmic face and $\mathrm{EF}$ for the exoplasmic face. $\mathrm{PF}_{\mathrm{u}}, \mathrm{PF}_{\mathrm{s}}$ and $\mathrm{EF}_{\mathrm{u}}$, $\mathrm{EF}_{\mathrm{s}}$ are protoplasmic (PF) and exoplasmic (EF) fracture faces in unstacked (u) and stacked (s) membranes respectively. Figure 1 shows the fracture face of the chloroplast membranes of the control and the evernic acid-treated samples.

Histograms of particle size (Figs. 2 and 3) on thylakoid membrane fracture faces $\mathrm{PF}_{\mathrm{s}}, \mathrm{PF}_{\mathrm{u}}, \mathrm{EF}_{\mathrm{s}}$ and $\mathrm{EF}_{\mathrm{u}}$, were obtained from photographs similar to Fig. 1. The relative frequency of particles smaller than $10 \mathrm{~nm}$ increased on the $\mathrm{EF}_{\mathrm{s}}$ face of the chloroplasts treated with evernic acid whereas the particles with a diameter bigger than $14 \mathrm{~nm}$ had decreased. On the $\mathrm{PF}$ face $\left(\mathrm{PF}_{\mathrm{s}}\right.$ and $\left.\mathrm{PF}_{\mathrm{u}}\right)$, the relative frequency of particles smaller than $10 \mathrm{~nm}$ increased in the thylakoids of chloroplasts from leaves treated with evernic acid compared with the control leaves.

The average diameter of particles on each face was lower in the treated samples than in the control ones (Table 3), except for the $\mathrm{EF}_{\mathbf{u}}$ face. Furthermore, the particle number on the $\mathrm{EF}_{\mathrm{s}}$ face was lower in the evernic acid-treated spinach leaves ( 925 particles $\left.\mu \mathrm{m}^{-2}\right)$ than in the control ones ( 1211 particles $\mu \mathrm{m}^{-2}$ ). No significant differences were found for this parameter on the other faces. The ratio of particle density on PF to that on EF, given as the coefficient of thylakoid membranes $\left(K_{\mathrm{mt}}\right)$, is also shown in Table 3 .

\section{DISCUSSION}

The changes in the amount of total chlorophyll as well as chlorophyll $a$ and $b$ in the evernic acid-treated samples indicate that certain aspects of photosynthetic physiology may be subject to variation.

Since the majority of the photosystem II centres are located in the stacked regions of the membrane systems, whereas the centre of photosystem I is found in unstacked regions (Miller, 1980) in treated plants, the reduction in the area of chloroplasts, in the amount 

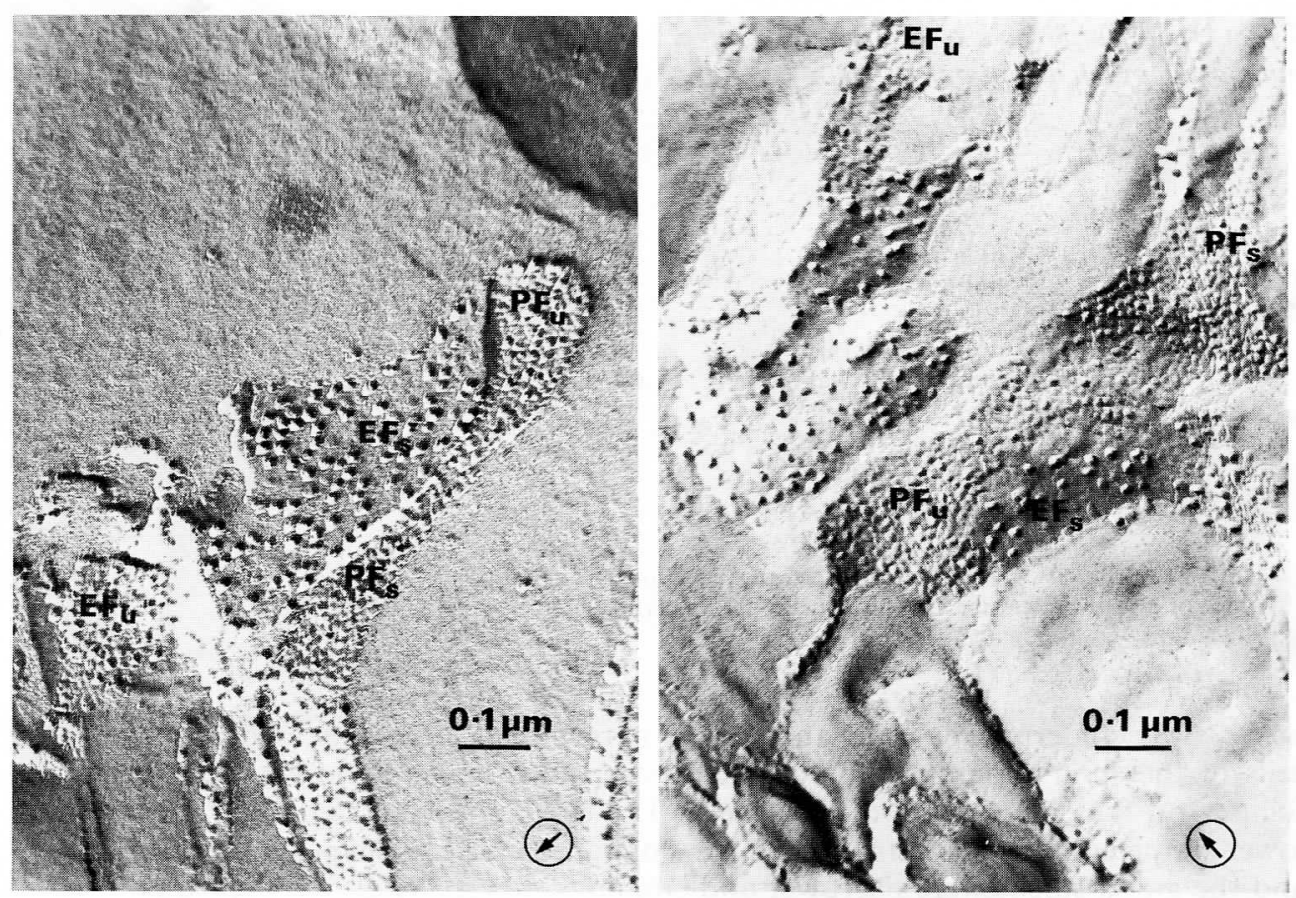

FIG. 1. Freeze-fracture characteristics of chloroplast membranes of spinach plants. A, Control. $\mathrm{B}$, Evernic acid-treated plant. $\mathrm{EF}_{\mathrm{s}}, \mathrm{EF}_{\mathrm{u}}, \mathrm{PF}_{\mathrm{s}}$ and $\mathrm{PF}_{\mathrm{u}}$, exoplasmic $(\mathrm{EF})$ and protoplasmic $(\mathrm{PF})$ fracture faces in stacked (s) and unstacked (u) membranes.

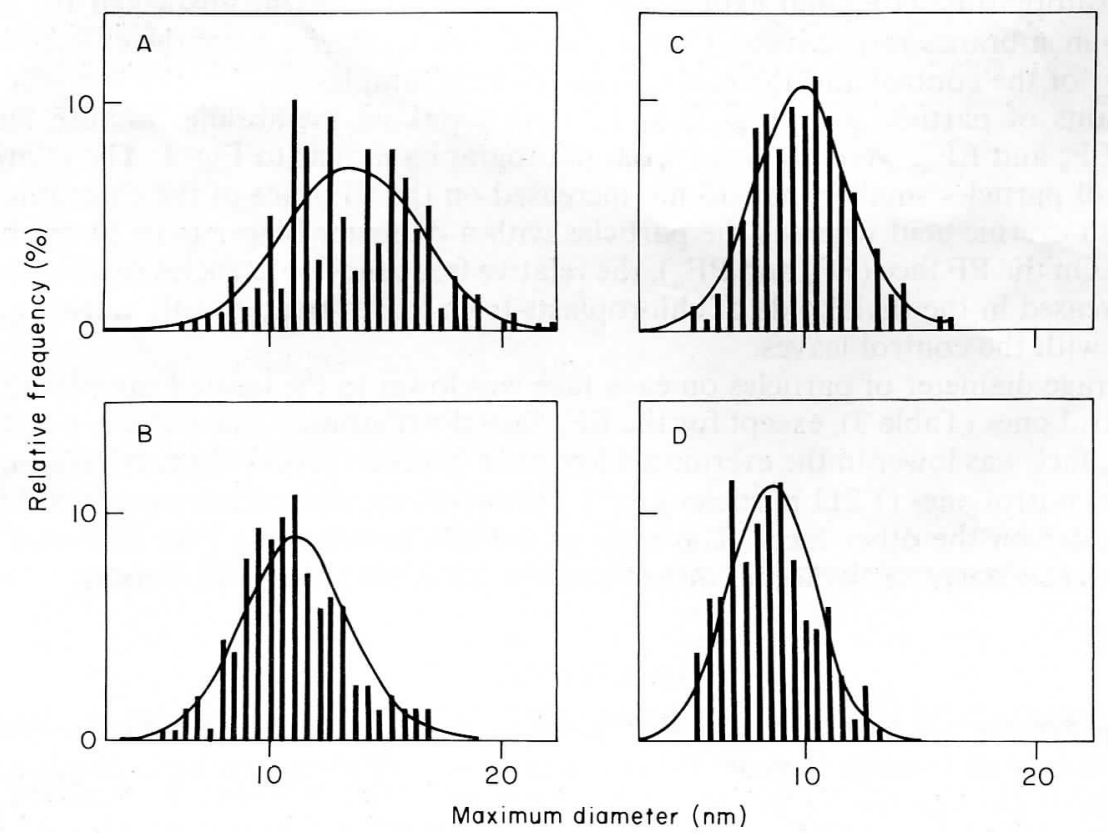

FIG. 2. Particle size histograms made from measurements on the EF and PF fracture face (stacked) of membranes of chloroplasts isolated from spinach leaves. Based on 500 particles. A, Control, EFs, $\bar{x}=13.54 \mathrm{~nm}, s=2.86 \mathrm{~nm}$; B, evernic acid EFs, $\bar{x}=11.03 \mathrm{~nm}, s=2.3 \mathrm{~nm} ; C$, Control, PFs, $\bar{x}=9.93 \mathrm{~nm}, s=1.97 \mathrm{~nm}$; D, evernic acid, PFs $\bar{x}=8.52 \mathrm{~nm}, s=1.84$. 


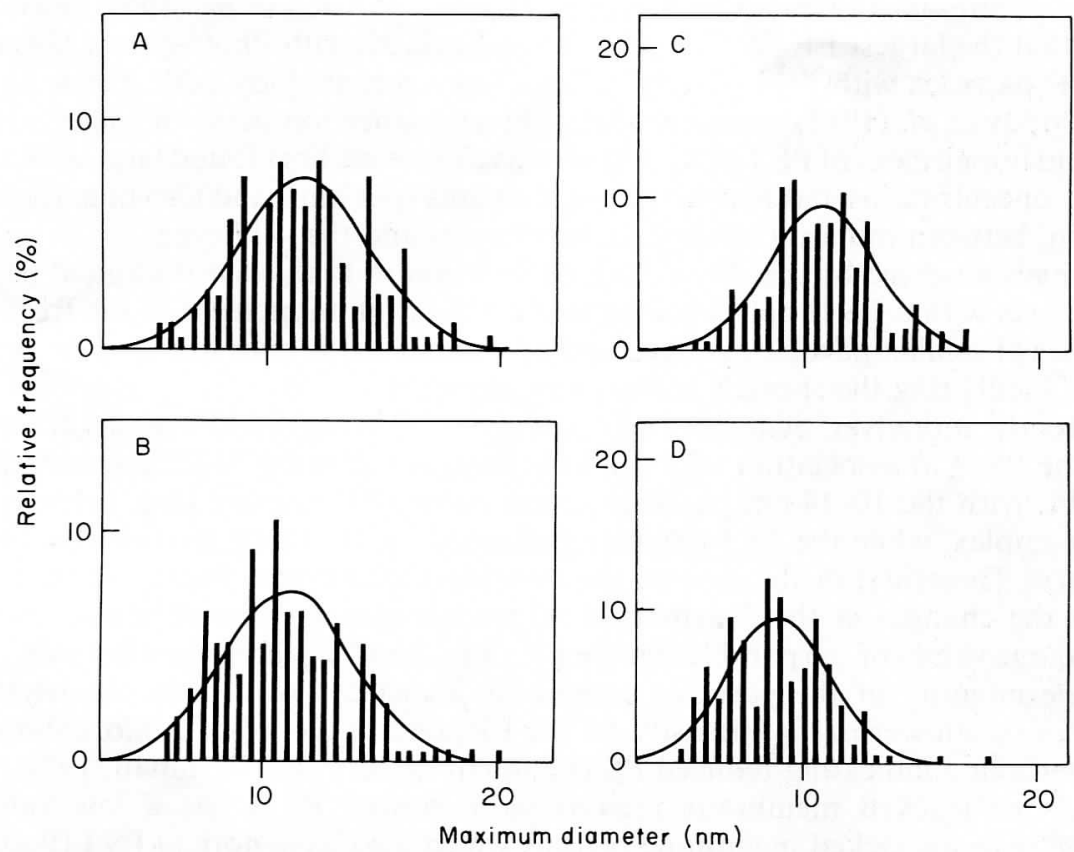

FIG 3. Particles size histograms made from measurements on the EF and PF fracture face (unstacked) of membranes of chloroplasts isolated from spinach leaves. Based on 500 particles. A, Control, EFu, $\bar{x}=11.48 \mathrm{~nm}, s=2.76 \mathrm{~nm}$; B, evernic acid, EFu, $\bar{x}=11 \mathrm{~nm}, s=2.8$; C, Control, PFu, $\bar{x}=10.7 \mathrm{~nm}$, $s=2 \cdot 19 ; \mathrm{D}$, evernic acid, PFu, $\bar{x}=8 \cdot 86 \mathrm{~nm}, s=2 \cdot 17 \mathrm{~nm}$.

T A B LE 3. Diameter and density of particles on the $P$ and $E$ complementary fracture faces of the chloroplast membranes for control and evernic-treated spinach plants

\begin{tabular}{llcc}
\hline Face & Treatment & $\begin{array}{c}\text { Particle size } \\
(\overline{\mathrm{x}}) \\
(\mathrm{nm})\end{array}$ & $\begin{array}{c}\text { Particle density } \\
(\overline{\mathrm{x}}) \\
\left(\mathrm{n} \mu \mathrm{m}^{-2}\right)\end{array}$ \\
\hline $\mathrm{EF}_{\mathrm{s}}$ & Control & $13 \cdot 54 \pm 2 \cdot 86^{*}$ & $1211 \pm 270^{*}$ \\
$\mathrm{EF}_{\mathrm{u}}$ & Evernic acid & $11 \cdot 03 \pm 2 \cdot 30^{*}$ & $925 \pm 271^{*}$ \\
& Control & $11 \cdot 48 \pm 2 \cdot 76$ & $737 \pm 133$ \\
$\mathrm{PF}_{\mathrm{s}}$ & Evernic acid & $11 \cdot 00 \pm 2 \cdot 80$ & $846 \pm 236$ \\
$\mathrm{PF}_{\mathrm{u}}$ & Control & $9 \cdot 93 \pm 1 \cdot 97^{*}$ & $1306 \pm 167$ \\
& Evernic acid & $8 \cdot 52 \pm 1 \cdot 84^{*}$ & $1405 \pm 238$ \\
$K_{\mathrm{mt}} \mathrm{PF}_{\mathrm{s}} / \mathrm{EF}_{\mathrm{s}}$ & Control & $10 \cdot 70 \pm 2 \cdot 19^{*}$ & $1358 \pm 223$ \\
& Evernic acid & $8 \cdot 86 \pm 2 \cdot 17^{*}$ & $1393 \pm 208$ \\
$K_{\mathrm{mt}} \mathrm{PF}_{\mathrm{u}} / \mathrm{EF}_{\mathrm{u}}$ & Control & $1 \cdot 07$ & \\
& Evernic acid & $1 \cdot 51$ & \\
& Control & $1 \cdot 84$ & \\
& Evernic acid & $1 \cdot 64$ & \\
\hline
\end{tabular}

Means \pm s.d.

Values of a specific feature are statistically different $(t$-test $)$ at $* P<0.01$.

of grana per chloroplast and, even more important, the decrease in stacking of thylakoidal membranes suggests the existence of alterations in the activity of the photosystems.

Since stacking is not the only condition for the PS II activity (Park and Nolan, 1974; Arntzen and Briantais, 1975), it was necessary also to observe the particles of the 
thylakoidal membranes revealed by freeze-fracturing. Arntzen et al. (1969) previously suggested that the largest EF particles might be associated with Photosystem II and the smallest PF particles with Photosystem I. In a more recent study with Pisum sativum mutants, Popov et al. (1981) demonstrated a direct connection between changes in the particles and impairment of PS I and PS II activity. These authors found large differences in particle concentrations and relative population area $\left(\right.$ per $\left.\mu \mathrm{m}^{2}\right)$ and also in particle size distribution, between mutant chloroplast membranes and the wild-type.

The changes observed by the above authors with regard to the distribution of particle size in mutants with a PS II deficiency basically consist of an increase in the frequency of the classes of smaller particle diameter and are similar to the ones found in the present study after incubating the spinach leaves in evernic acid.

Very recently, moreover, Semenova and Ladigyn (1984) suggested a model according to which the PS II in association with the LH complex forms the 14-22 nm particles of the EF face, with the 10-14 nm particles found on the EF fracture face, belonging to the PS II complex, while the PS I complex is formed by 10-14 nm particles on the PF fracture face. Therefore, in the case of the thylakoid membranes incubated in evernic acid, both the changes in the distribution of particle size, mentioned above, and the smaller average values of the particles on the $\mathrm{EF}_{\mathrm{s}}, \mathrm{PF}_{\mathrm{s}}$, and $\mathrm{PF}_{\mathrm{u}}$ faces must be understood as a change integrity of the particles commonly associated with both photosystems. Furthermore, the lower particle density on the $\mathrm{EF}_{\mathrm{s}}$ face in the treated chloroplasts can also be interpreted indicating reduced PS II content (Miller and Cushman, 1979).

The $K_{\mathrm{mt}}$ for stacked membrane regions with normal PS II has a low value in comparison with unstacked membrane regions which also have normal PS I (Popov et al., 1981). An increase of $K_{\mathrm{mt}}$ correlates with a loss in PS II activity (Popov et al., 1977). We have observed in our study that the $K_{\mathrm{mt}}$ for the stacked regions is higher for the evernic acid-treated samples (1.51) than for the controls (1.07), suggesting a loss of photosystem II activity. The changes in the membrane particles on both fracture faces of thylakoid membranes in the evernic acid-treated spinach plants indicate an important potential effect of evernic acid on photosynthesis. Since previous studies (Ascaso et al., 1980; Orus and Ascaso, 1982) showed that epiphytic lichen hyphae reach the xylem it is probable that the phenolic substances from the epiphytic thallus (e.g. evernic acid) reach the xylem and are translocated to the phorophyte leaves, producing similar changes in their chloroplasts.

\section{ACKNOWLEDGEMENTS}

We thank Dr D. H. Brown (University of Bristol) for correcting the English text. Thanks are also due to Mrs T. Carnota and Mr F. Pinto for technical assistance. This work was supported by a research grant of the Comisión Asesora de Investigación Científica y Técnica, no. $365 / 81$.

\section{LITERATURE CITED}

Arnon, D. I., 1949. Copper enzymes in isolated chloroplast. Polyphenol oxidases in Beta vulgaris. Plant Physiology 24, 1-15.

Arntzen, C. J. and Briantais, J. M., 1975. Chloroplast structure and function. In Bioenergetics of Photosynthesis ed. Govindjee, G. Academic Press, New York.

Arntzen, C. J., Dilly, R. A. and Crane, F. L., 1969. A comparison of chloroplast membrane surfaces visualized by freeze-etch and negative staining techniques; and ultrastructural characterization of membrane fractions obtained from digitonin treated spinach chloroplast. Journal of Cell Biology 43, 16-31.

Asahina, Y. and Kurokawa, S., 1952. On the harmful effects of epiphytic lichens upon the higher plants. Miscellaneous Reports-Research Institut for Natural Resources 25, 83-6.

Ascaso, C., Gonzalez, C. and Vicente, C., 1980. Epiphytic Evernia prunastri: Ultrastructural facts. Cryptogamie Bryologie Lichenologie 1, 43-51. 
Ascaso, C., Orus, I. and Estevez, P., 1983. Chloroplast crystalloids and other alterations in response to lichen substances. Photosynthetica 17, 198-203.

Branton, D., Bullivant, S., Gilula, N. B., Karnovsky, M. J., Moor, H., Mühlethaler, K., Northcote, D. H., Packer, L., Satir, B., Satir, P., Speth, V., Staehelin, L. A., Steere, R. L. and Weinstein, R., 1975. Freeze-etching nomenclature. Science 190, 54-6.

Dauriac, H. and Rondon, Y., 1976. Quelques aspects des propriétés d'un lichen: le Letharia vulpina (L.) Hue en biologie experimentale. I. Action sur la germination du blé et le developpment de l'ail. Bulletin de la Societe Botanique de France 123, 235-41.

Estevez, M. P., Orus, M. I., and Vicente, C., 1982. Desfoliación de Quercus rotundifolia inducida por Evernia prunastri en condiciones naturales o simuladas. Libro homenaje al Profesor D. Florencio Bustinza Lachiondo, pp. 117-31, eds. Vicente, C. and Municio, A. M. Editorial de la Universidad Complutense, Madrid.

Goodenough, U. W. and Staehelin, L. A., 1971. Structural differentiation of stacked and unstacked chloroplast membranes. Journal of Cell Biology 48, 594-619.

Hale, M. E. Jr., 1983. The Biology of Lichens. Edward Arnold, London.

MiLleR, K. R., 1980. A chloroplast membrane lacking photosystem I. Changes in unstacked membrane regions. Biochimica et Biophysica Acta 592, 143-52.

Miller, K. R. and Cushman, R. A., 1979. A chloroplast membrane lacking photosystem II. Thylakoid staking in the absence of the photosystem II particle. Biochimica et Biophysica Acta 546, 481-97.

Moor, H. and Mühlethaler, K., 1963. Fine structure in frozen-etched yeast cells. Journal Cell Biology 17, 609-27.

Orus, I. and Ascaso, C., 1982. Localización de hifas liquénicas en los tejidos conductores de Quercus rotundifolia Lam. Collectanea Botanica 13, 325-38.

Orus, I., Estevez, P. and ViCente, C., 1981. Manganese depletion in Chloroplasts of Quercus rotundifolia during chemical simulation of lichen epiphytic states. Physiologia Plantarum 52, 263-6.

PARK, R. B. and Nolan, W. G., 1974. The chemical composition and photochemical activity of chloroplast grana and stroma lamellae. Annals of the New York Academy of Sciences 227, 580-6.

Popov, V. I., Matorin, D. N., Gostimsky, S. V., Tageeva, S. V. and AllakhVerdov, B. L., 1981. Ultrastructural organization of Chloroplast membranes in Mutants of Pisum sativum L. with Impaired Activity in the Photosystems. Planta 151, 512-24.

Popov, I. V., LAdygin, V. G. and TAGEeva, S. V., 1977. Supermolecular organization of chloroplast membranes in Chlamydomonas reinhardii mutants with inactive photosystems. Izvestiya Akademii Nauk SSSR. Seriya Biologicheskaya 6, 856-68.

RAMAUT, J. L. and ThONAR, F., $1972 a$. Inhibition de la germination de differentes graines d'angiospermes par Evernia prunastri (L.) Ach. Anales de Química 68, 575-95.

Ramaut, J. L. and ThONAR, F., $1972 b$. Inhibition de la germination de differentes graines d'angiospermes par Evernia prunastri (L.) Ach. $2^{\mathrm{eme}}$ partie. Anales de Química 68, 597-607.

REYNOLDS, S., 1963. The use of lead citrate at high $\mathrm{pH}$ as an electron opaque stain in electron microscopy. Journal of Cell Biology 17, 208-12.

RichaRdson, D. H. S., 1974. The Vanishing Lichens. Their History, Biology and Importance. Hafner Press, New York.

Semenova, G. A. and LADygin, V. G., 1984. Topography of thylakoid membranes of chloroplasts based on the analysis of Chlamydomonas mutants deficient in chlorophyll-protein complexes. Photosynthetica 18, $50-6$.

SPURR, A. R., 1969. A low viscosity epoxy resin embedding medium for electron microscopy. Journal of Ultrastructural Research 26, 31-43.

Whatley, F. R. and ARnON, D. I., 1963. Photosynthetic phosphorylation in plants. Methods of Enzymology 6, 308-13. 